\title{
Towards an all-fiber system for detection and monitoring of ammonia
}

Adamu, Abubakar Isa; Dasa, Manoj Kumar; Habib, Md Selim; Amezcua-Correa, Rodrigo; Bang, Ole; Markos, Christos

\section{Published in:}

Proceedings of SPIE

Link to article, DOI:

$10.1117 / 12.2509575$

Publication date:

2019

Document Version

Publisher's PDF, also known as Version of record

Link back to DTU Orbit

Citation (APA):

Adamu, A. I., Dasa, M. K., Habib, M. S., Amezcua-Correa, R., Bang, O., \& Markos, C. (2019). Towards an allfiber system for detection and monitoring of ammonia. In Proceedings of SPIE (Vol. 10895). [1089506] SPIE International Society for Optical Engineering. Proceedings of SPIE - The International Society for Optical Engineering https://doi.org/10.1117/12.2509575

\section{General rights}

Copyright and moral rights for the publications made accessible in the public portal are retained by the authors and/or other copyright owners and it is a condition of accessing publications that users recognise and abide by the legal requirements associated with these rights.

- Users may download and print one copy of any publication from the public portal for the purpose of private study or research.

- You may not further distribute the material or use it for any profit-making activity or commercial gain

- You may freely distribute the URL identifying the publication in the public portal 


\section{Towards an all-fiber system for detection and monitoring of ammonia}

Abubakar I. Adamu, Manoj K. Dasa, Md. Selim Habib, Rodrigo Amezcua-Correa, Ole Bang, et al.

Abubakar I. Adamu, Manoj K. Dasa, Md. Selim Habib, Rodrigo AmezcuaCorrea, Ole Bang, Christos Markos, "Towards an all-fiber system for detection and monitoring of ammonia," Proc. SPIE 10895, Frontiers in Biological Detection: From Nanosensors to Systems XI, 1089506 (7 March 2019); doi: $10.1117 / 12.2509575$

SPIE. Event: SPIE BiOS, 2019, San Francisco, California, United States 


\title{
Towards an all-fiber system for detection and monitoring of ammonia
}

\author{
Abubakar I. Adamu*a, Manoj K. Dasa, ${ }^{a}$ Md. Selim Habib, ${ }^{\text {b }}$ Rodrigo Amezcua-Correa,${ }^{b}$ \\ Ole Bang, ${ }^{\mathrm{a}, \mathrm{c}}$ and Christos Markos ${ }^{\mathrm{a}}$ \\ ${ }^{a}$ DTU Fotonik, Department of Photonics Engineering, Technical University of \\ Denmark, Kgs. Lyngby 2800, Denmark \\ ${ }^{b}$ CREOL, The College of Optics and Photonics, University of Central Florida, \\ Orlando, FL-32816, USA \\ ${ }^{c}$ NKT Photonics, Blokken 84, Birkerdd 3460, Denmark \\ *abisa@fotonik.dtu.dk
}

\section{ABSTRACT}

Detection of ammonia based on an all-fiber configuration is reported. The system consists of a hollowcore photonic-bandgap (HC-PBG) fiber with $20 \mu \mathrm{m}$ core diameter and transmission window from 1490 to $1680 \mathrm{~nm}$. Absorption bands of ammonia at $\sim 1538 \mathrm{~nm}$ are targeted using a supercontinuum source with central wavelength at $1550 \mathrm{~nm}$. We present the method of achieving a complete fiber system while addressing the gas entry/exit path through the HC-PBG. Analysis of the ammonia absorbance in the fiber with respect to fiber length and response time is investigated. By operating in the near infrared, we demonstrate how the proposed system addresses several challenges associated with fiberbased gas-sensing, using readily available commercial components.

Keywords: Absorption spectroscopy, Supercontinuum lasers, Hollow-core fibers.

\section{INTRODUCTION}

Ammonia is the most abundant alkaline gas in the atmosphere and although ammonia is necessary for the growth of plants and crops, an excess of it causes environmental pollution and is a precursor for the formation of particulate matter and acidification ${ }^{1}$. The primary source of ammonia in the atmosphere is from agriculture; through intensive livestock farming, fertilizer production and natural decomposition of manure.

Ammonia levels in the atmosphere can be very low, reports show the level of ammonia above oceans are in sub-parts per billion (ppb) level ${ }^{2,3}$, but concentrations at areas of intensive farming go as high as $10 \mathrm{ppm}$ or more ${ }^{3}$. Therefore any sensor aimed for monitoring ammonia in such environments will require high sensitivity. There are a number of ways to detect ammonia in high concentrations, even though the human nose is very sensitive to ammonia and can sense the pungent smell at concentrations from $5 \mathrm{ppm}$ in open atmosphere ${ }^{4,5}$, it fails to detect lower concentrations ${ }^{2,6}$. Therefore, a different method is necessary to detect lower concentrations of ammonia in the atmosphere than $5 \mathrm{ppm}$.

Gas sensing technology is certainly not a new research area; many articles have been published on various gas sensors for various applications such as automobile gas emission monitoring ${ }^{7,8}$, fire alarms ${ }^{9}$, inspection of dairy products for food industries ${ }^{10}$, etc. Most of these gas sensors are developed 
to target specific gases and although some of the sensors have reached commercialization, they still lack the ability for monitoring other gases such as ammonia. For example, sensors used for fire and smoke detectors are mostly based on photoelectric or air ionization effects- where a change in the density of air in the gas chamber triggers the alarm. Oxide semiconductors have been widely studied for gas sensing, and a major setback has been the issue of selectivity ${ }^{11}$ and operational temperature. In attempts to increase the selectivity, dopants and additives have been used to modulate the selectivity to some extent ${ }^{11,12}$ but the operational temperature still goes as high as $300{ }^{\circ} \mathrm{C}$ for detection at 1000 ppm level $^{11}$. A more versatile, highly sensitive and selective system is necessary for the detection and monitoring of ammonia in the atmosphere. Gas absorption spectroscopy offers a strong advantage in terms of selectivity. By utilizing the unique absorption spectrum of molecules, it is possible to target a specific gas, and the sensitivity of the system can be improved by enhancing the light-matter interaction. To this end, Hollow-Core Photonic Band Gap (HC-PBG) fibers have attracted huge attention by virtue of their promise to deliver a unique range of optical properties that are simply not possible with conventional solid core fiber types. ${ }^{13-16}$ In HC- PBG fibers, over than $99 \%$ of the power in the optical mode is confined within the hollow core. This gives the provision of ultralow (a tunable) optical nonlinearity, excellent power handling capabilities, low latency, and even offers the prospect of ultralow losses, both at conventional wavelengths (e.g., around $1550 \mathrm{~nm}$ ) and at longer wavelengths into the mid-IR where solid core silica fibers fail ${ }^{17}$. Above all, the possibility of light-matter interaction within the core of these fibers (both HC-PBG and antiresonant) is of great importance for gas sensing applications. This technology has also recently enabled their use for extreme gas-based nonlinear optics covering the extreme ultraviolet up to mid-IR spectral region ${ }^{18-21}$.

In this paper, we demonstrate the detection of ammonia using a commercial HC-PBG fiber and investigate the absorbance of ammonia in different lengths of the fiber and also the gas filling time. The proposed system is based on an all-fiber configuration thus enhancing its robustness, while mechanical splices are used for the gas entry and exit point between the HC-PBG and single mode fibers. The system was found to exhibit highly repeatability and it has a response time of $<5$ seconds under only 0.5 bar pressure above the atmospheric pressure. The system can be readily tuned to target other polyatomic gas molecules with absorption bands in the near IR.

\section{EXPERIMENTAL SETUP AND METHODOLOGY}

A commercially available 19-cell HC-PBG fiber (NKT Photonics A/S) was used during the experiment. After cleaving, the facet of the fiber was inserted in a ferrule to allow only a small part to extrude out, as shown in figures 1(i) \& (ii). One end of the HC-PBG is mechanically spliced to the SC laser source with a ferrule-mating sleeve (details of the SC laser are reported in our previous study ${ }^{22}$ ). The connectorization is done by carefully placing the cleaved fiber ends into the ferrule, and glued at the end to provide mechanical strength, the ferrules are then matted with a mating sleeve and both procedures were performed under an optical microscope for better precission. The sleeve has a slit of about $500 \mu \mathrm{m}$, where gas diffuses into the fiber. The other end of the HC-PBG fiber was connected to a spectrometer for spectral analysis. Nitrogen gas was used as reference/purge gas because it has no absorption in the near IR. 

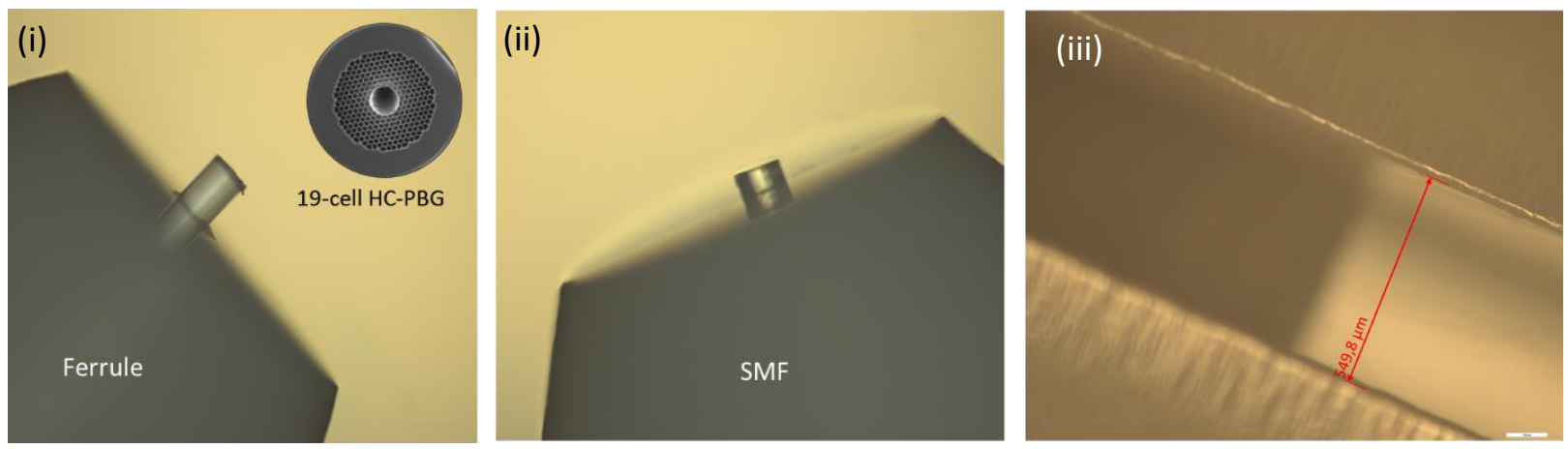

Figure 1: Mechanical splice. (i) \& (ii) The two ends of the hollow core fiber are inserted in a ferrule. The core diameter is $\sim 20 \mu \mathrm{m}$ and total fiber diameter is $\sim 125 \mu \mathrm{m}$. The two ferrules are matted together with a mating sleeve (iii) Sleeve has an opening of $\sim 550 \mu \mathrm{m}$ for gas passage.

For every measurement, nitrogen gas was used to neutralize the system prior to recording of the background measurement. Ammonia gas was then passed and the absorption spectrum was recorded for every case. During the data acquisition, the pressure was maintained fixed at $1 \mathrm{~atm}$, to ensure ammonia molecules in the fiber are not compressed. This cycle repeated several times for each fiber length and the average response is finally taken.

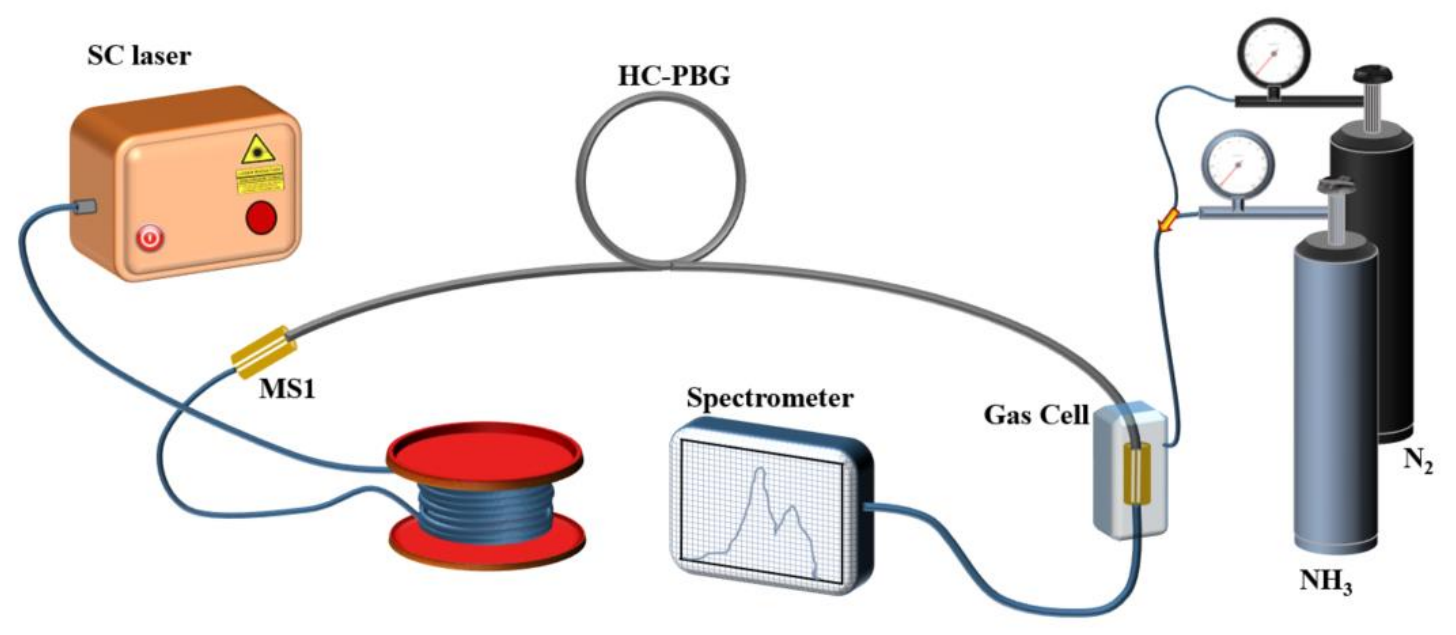

Figure 2: Schematic of the all-fiber ammonia sensing. An SC laser with central wavelength at $1550 \mathrm{~nm}$ is mechanically spliced (MS1) to an HC-PBG fiber. Ammonia gas is passed through a gas cell into the entry splice point, to create a pressure difference. A spectrometer is used to analyze the result. Nitrogen gas (N2) is used as the background/purging gas.

The spectrum was recorded with an ocean optics spectrometer (NIRQuest512) and the output power at the end of the hollow core fiber (with nitrogen filled) was set to $\sim 1 \mathrm{~mW}$ to avoid device saturation.

\section{4: RESULTS AND DISCUSSION}

The governing theory for absorption spectroscopy is embodied in the Beer-Lambert law ${ }^{17}$. The law states that the ratio of the Intensity of transmitted light (I) and initial reference intensity $\left(\mathrm{I}_{0}\right)$ of laser radiation is 
exponentially related to the concentration of the gas, path length and the molar absorptivity of the gas. This is denoted as:

$$
\frac{I}{\mathrm{I}_{0}}=10^{-\varepsilon(\lambda) c L}
$$

Where $I$ and $I_{0}$ are the transmitted and initial laser radiation respectively, $c$ stands for the concentration of the absorbing medium (gas) units in $\mathrm{M}(\mathrm{mol} / \mathrm{L}), \varepsilon(\lambda)$ stands for the wavelength dependant molar absorptivity of the gas (in $\mathrm{L} / \mathrm{mol} . \mathrm{cm}$ ), $L$ is the path length for the light-matter interaction (in cm). From Eq. 1, it is clear that increasing the length of the fiber allows the detection of lower concentrations of gas, as previously demonstrated in polymer fibers ${ }^{18}$. In our work, the lengths of the fiber were varied from $45 \mathrm{~cm}$ to $15 \mathrm{~cm}$, the filling time was found to be about 8 seconds for the $45 \mathrm{~cm}$ length, and $<5 \mathrm{~seconds}$ for the $15 \mathrm{~cm}$ long fiber. The absorbance of ammonia in the fiber is determined as:

$$
A=\log \left(\frac{I}{\mathrm{I}_{0}}\right)=\varepsilon l c
$$

Where $\varepsilon$ is absorptivity (as a given wavelength), $\mathrm{c}$ is the concentration and $l$ stands for the path length or fiber length.
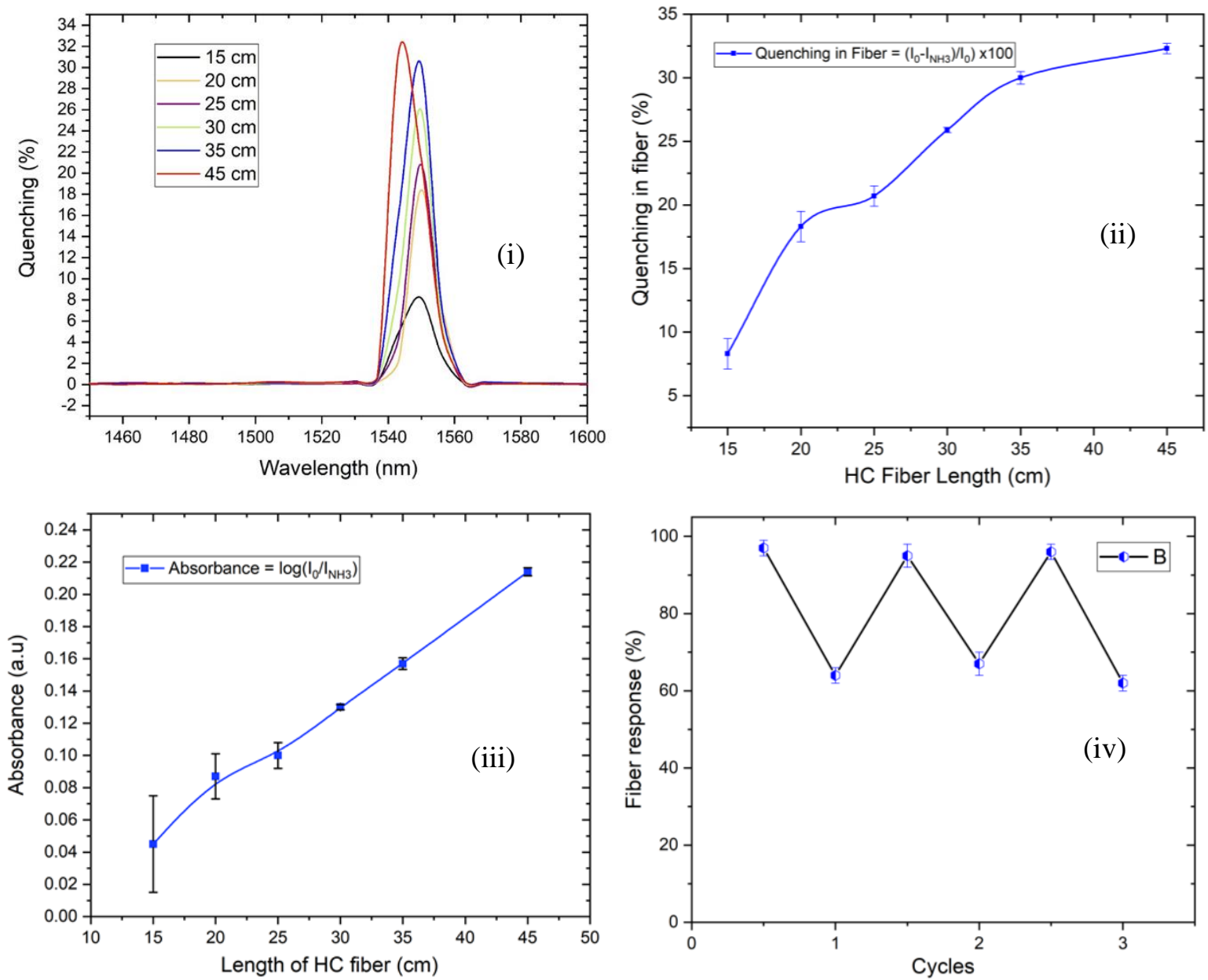
Figure 3: (i) Variation of quenching in the fiber with respect to wavelength. (ii) Calculated quenching in the fiber with respect to the hollow core fiber length. (iii) Calculated absorbance with respect to the length of the hollow core fiber. (iv) Repeatability of all fiber detection system.

Additionally, we can see from the results that the standard deviation in the absorbance for shorter lengths of fiber were higher than in longer lengths which invariably indicates that at long fiber lengths, there is higher light interaction with volatile ammonia molecules, and thus the accuracy of the absorbance was higher. The quenching is important in establishing a threshold for measurements, where different wavelengths are used to target multiple gasses. ${ }^{14}$

\section{CONCLUSION}

In conclusion, a compact all-fiber system that constitutes an HC-PBG is used for detection of trace ammonia molecules. The PBG fiber with central transmission band at $1550 \mathrm{~nm}$ is used to target the $\mathrm{V} 1+\mathrm{V} 3$ ammonia absorption band in the near IR regime $(1538 \mathrm{~nm})$. Using a homebuilt supercontinuum source, spectrum analyzer, a telecom SMF-28 fiber, ferrule and mating sleeves, a compact all-fiber system is proposed that allows for effective gas detection. The enhanced light-gas interaction in the $20 \mu \mathrm{m}$ core PBG fiber core allows for accurate monitoring of the ammonia based on absorption spectroscopy. The proposed system is robust, cost-effective and based on readily available commercial components which proffer solutions to the challenges faced in existing gas sensors. Ammonia molecules were detected in less than 5 seconds response time using a few meters of PBG fiber with high repeatability compared to hitherto techniques. Experiments on sensitivity and limit of detection for $45 \mathrm{~cm}$ length $\mathrm{HC}-\mathrm{PBG}$ is envisaged in future works.

\section{ACKNOWLEDGMENTS}

The authors will like to acknowledge funding from Innovation Fund Denmark Innovation Fund Denmark (6150-00030B and 4107-00011A), Det Frie Forskningsråd (DFF) (4184-00359B and 802200091B), Marie Sklodowska-Curie grant agreement No. 722380, Army Research Office (ARO) (W911NF-17-1-0501 \& W911NF-12-1-0450) and the Air Force Office of Scientific Research (AFOSR) FA9550-15-10041.

\section{REFERENCES}

1. Schauberger, G. et al. Impact of global warming on the odour and ammonia emissions of

livestock buildings used for fattening pigs. Biosyst. Eng. 175, 106-114 (2018).

2. Timmer, B., Olthuis, W. \& Berg, A. van den. Ammonia sensors and their applications - a review.

Sens. Actuators B Chem. 107, 666-677 (2005).

3. Mount, G. H. et al. Measurement of atmospheric ammonia at a dairy using differential optical absorption spectroscopy in the mid-ultraviolet. Atmos. Environ. 36, 1799-1810 (2002). 
4. Michaels, R. A. Emergency planning and the acute toxic potency of inhaled ammonia. Environ. Health Perspect. 107, 617-627 (1999).

5. van Thriel, C. et al. From chemosensory thresholds to whole body exposures-experimental approaches evaluating chemosensory effects of chemicals. Int. Arch. Occup. Environ. Health 79, 308-321 (2006).

6. Erisman, J. W. et al. Instrument development and application in studies and monitoring of ambient ammonia. Atmos. Environ. 35, 1913-1922 (2001).

7. Bishop, G. A., Starkey, J. R., Ihlenfeldt, A., Williams, W. J. \& Stedman, D. H. IR long-path photometry: a remote sensing tool for automobile emissions. Anal. Chem. 61, 671A-677A (1989).

8. Ueda, T., Nagano, T., Okawa, H. \& Takahashi, S. Zirconia-based amperometric sensor using LaSr-based perovskite-type oxide sensing electrode for detection of NO2. Electrochem. Commun. 11, 1654-1656 (2009).

9. Chen, S.-J., Hovde, D. C., Peterson, K. A. \& Marshall, A. W. Fire detection using smoke and gas sensors. Fire Saf. J. 42, 507-515 (2007).

10. Sberveglieri, V., Núñez Carmona, E. \& Pulvirenti, A. Detection of Microorganism in Water and Different Food Matrix by Electronic Nose. in Sensing Technology: Current Status and Future Trends III (eds. Mason, A., Mukhopadhyay, S. C. \& Jayasundera, K. P.) 243-258 (Springer International Publishing, 2015). doi:10.1007/978-3-319-10948-0_12

11. Aslam, M. et al. A highly selective ammonia gas sensor using surface-ruthenated zinc oxide. Sens. Actuators Phys. 75, 162-167 (1999).

12. Uozumi, G., Miyayama, M. \& Yanagida, H. Fabrication of a CuO-infiltrated ZnO composite and its gas sensing properties. J. Mater. Sci. 32, 2991-2996 (1997). 
13. Poletti, F., Petrovich, M. N. \& Richardson, D. J. Hollow-core photonic bandgap fibers: technology and applications. Nanophotonics 2, 315-340 (2013).

14. Adamu, A. I., Ozturk, F. E. \& Bayindir, M. Binary coded identification of industrial chemical vapors with an optofluidic nose. Appl. Opt. 55, 10247-10254 (2016).

15. Markos, C., Travers, J. C., Abdolvand, A., Eggleton, B. J. \& Bang, O. Hybrid photoniccrystal fiber. Rev. Mod. Phys. 89, 045003 (2017).

16. Markos, C., Antonopoulos, G. \& Kakarantzas, G. Broadband Guidance in a Hollow-Core Photonic Crystal Fiber With Polymer-Filled Cladding. IEEE Photonics Technol. Lett. 25, $2003-$ 2006 (2013).

17. Adamu, A. I. et al. Supercontinuum generation from deep-UV to mid-IR in a noble gas-filled fiber pumped with ultrashort mid-IR pulses. in Advanced Photonics 2018 (BGPP, IPR, NP, NOMA, Sensors, Networks, SPPCom, SOF) (2018), paper JTu6E.2 JTu6E.2 (Optical Society of America, 2018). doi:10.1364/BGPPM.2018.JTu6E.2

18. Habib, M. S. et al. Multi-stage generation of extreme ultraviolet dispersive waves by tapering gas-filled hollow-core anti-resonant fibers. Opt. Express 26, 24357-24371 (2018).

19. Habib, M. S., Markos, C., Bang, O. \& Bache, M. Soliton-plasma nonlinear dynamics in midIR gas-filled hollow-core fibers. Opt. Lett. 42, 2232-2235 (2017).

20. Travers, J. C., Chang, W., Nold, J., Joly, N. Y. \& Russell, P. S. J. Ultrafast nonlinear optics in gas-filled hollow-core photonic crystal fibers [Invited]. JOSA B 28, A11-A26 (2011).

21. Ermolov, A., Mak, K. F., Frosz, M. H., Travers, J. C. \& Russell, P. S. J. Supercontinuum generation in the vacuum ultraviolet through dispersive-wave and soliton-plasma interaction in a noble-gas-filled hollow-core photonic crystal fiber. Phys. Rev. A 92, 033821 (2015). 
22. Dasa, M. K. et al. High-pulse energy supercontinuum laser for high-resolution spectroscopic photoacoustic imaging of lipids in the 1650-1850 nm region. Biomed. Opt. Express 9, 1762-1770 (2018). 